\title{
Farklı yüzey işlemlerinin zirkonyanın ağız içi tamirine etkisi ${ }^{*}$
}

\author{
Daime Cengiz ${ }^{\alpha}$, Pınar Çevik $^{\beta}$ \\ Selcuk Dent J, 2017; 4: $52-58$ (Doi: 10.15311/1441.306095) \\ Bașvuru Tarihi: 13 Nisan 2017 \\ Yayına Kabul Tarihi: 13 Haziran 2017
}

\section{öz}

Farklı yüzey işlemlerinin zirkonyanın ağız içi tamirine etkisi

Amaç: Bu çalışmanın amacı, zirkonya yüzeyine uygulanan farklı yüzey işlemlerinin yaşlandırma sonrası kompozit rezin ve zirkonya arasındaki makaslama bağlanma dayanımına etkisini incelemektir.

Gereç ve Yöntemler: 40 adet sinterlenmiş zirkonya örnek $(19 \times 15 \times 2 \mathrm{~mm})$ dört farklı yüzey işlemi grubuna ayrıldı $(n=10)$ : Grup 1, elmas frez ile aşındırma; Grup 2, $30 \mu \mathrm{m}$ Al2O3 ile tribokimyasal silika kaplama; Grup 3, $50 \mu \mathrm{m}$ Al2O3 ile kumlama ve Grup 4, $110 \mu \mathrm{m} \mathrm{Al2O3} \mathrm{ile} \mathrm{kumlama} \mathrm{grubu.} \mathrm{Yüzey} \mathrm{işlemi} \mathrm{gören}$ zirkonya örneklere adeziv fosfat monomeri uygulanıp polimerize edildi. Kompozit rezin polimerizasyonunu takiben örnekler termal yaşlandırmaya ( $x 1000,5-55^{\circ} \mathrm{C}, 30$ saniye) tabi tutuldu. Örneklere hızı $0.5 \mathrm{~mm} /$ dakika olan üniversal test cihazı ile makaslama bağlanma dayanımı testi uygulandı. Test sonrası kırıma tipleri adeziv veya karma tip başarısızlık olarak kaydedildi. İstatistiksel analiz tek yönlü varyans analizi (ANOVA) ve Tukey HSD testleri kullanılarak yapıldı $(p<0.05)$.

Bulgular: ANOVA sonuçlarına göre gruplar arası makaslama bağlanma dayanımı değerleri istatistiksel olarak anlamlı bulunmuştur $(p<0.05)$. Bağlanma dayanımı değerleri her bir grup için sırasıyla: Grup 1 (21.51 \pm 1.72$)$, Grup 2 (28.44 \pm 3.91$)$, Grup 3 $(19.93 \pm 2.31)$, Grup $4(23.38 \pm 4.35)$ Megapaskal olarak kaydedilmiştir. Tüm gruplar arası en yüksek bağlanma dayanımı değeri tribokimyasal silika kaplama grubunda $(p<0.05)$ olup Grup 1,3 ve 4 arasında istatistiksel olarak anlamlı bir fark bulunamamıştır $(p>0.05)$. Tüm gruplarda adeziv tip başarısızlık gözlenmiştir.

Sonuç: Tüm gruplar klinik olarak kabul edilebilir bağlanma dayanımı değerleri göstermiştir. Bununla birlikte tribokimyasal silika kaplama yönteminin zirkonya ile kompozit rezin arasındaki bağlanma dayanımını anlamlı derecede artırdığı gözlenmiştir.

\section{ANAHTAR KELIMELER}

Dental, hava abrazyonu, kayma mukavemeti, prostodonti, silikon dioksit

Zirkonyum dioksit yüksek dayanıklılık ve kırılma sertliği gibi üstün mekanik özelliklere sahip tam seramik sistemlerden biridir. ${ }^{1}$ Zirkonyanın kırılma direncinin 9-10 $\mathrm{MPa} / \mathrm{m}^{1 / 2}$ ve bükülme dayanımının 900-1200 $\mathrm{MPa}$

\section{ABSTRACT \\ Effects of various surface treatments on intraoral repair of zirconia}

Background: The aim of this study was to evaluate the effects of different surface treatments on shear bond strength between composite resin and zirconia after thermocycling.

Methods: Forty sintered zirconia specimens $(19 \times 15 \times 2 \mathrm{~mm})$ were divided into four groups $(n=10)$ according to various surface treatments: Group 1, grinding; Group 2, tribochemical silica coating with $30 \mu \mathrm{m}$ Al2O3 particles (CoJetTM); Group 3, airparticle abrasion with $50 \mu \mathrm{m} \mathrm{Al} 2 \mathrm{O} 3$ particles and Group 4, airparticle abrasion with $110 \mu \mathrm{m}$ Al2O3 particles. Adhesive phosphate monomer was applied to the treated surface of all the specimens and polymerized. After composite resin polymerization, the specimens were thermocycled $\left(5-55{ }^{\circ} \mathrm{C}\right.$, $1000 x, 30$ seconds). Shear bond strengths of the specimens were determined with a universal testing machine at a cross head speed of $0,5 \mathrm{~mm} /$ minute. Failure types were classified as adhesive or mixed. The data of bond strengths were statistically analyzed using ANOVA and Tukey HSD tests $(p<0.05)$.

Results: ANOVA results indicated that there was statistically significant difference between the groups $(p<0.05)$. Bonding groups exhibited the following shear bond values in Megapascal:

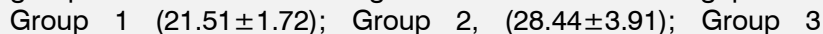
(19.93 \pm 2.31$)$; Group 4 (23.38 \pm 4.35$)$, respectively. Tribochemical silica coating revealed the highest shear bond strength value $(p<0.05)$, while there was not statistically significant difference between Group 1, 3 and 4. All groups revealed adhesive type failure.

Conclusion: All surface treatments showed clinically acceptable shear bond strength values. However, the results revealed that tribochemical silica coating provided a significant increase in shear bond strength between composite resin and zirconia.

\section{KEYWORDS}

Dental, air abrasion, shear strength, prosthodontics, silicon dioxide

olduğu bildirilmiştir. ${ }^{2}$ Zirkonyanın mekanik özelliklerinin iyi olması, kuvvetli yüklere maruz kalan posterior bölgede çok üyeli köprü olarak kullanılmasına imkân vermektedir. $^{3}$

\footnotetext{
* Bu çalışmanın ön pilot kısmı, 24-27 Nisan 2014 tarihleri arasında Belgrat/Strbistan'da düzenlenmiş olan 19. Uluslararası BaSS (Congress of the Balkan Stomatological Society) Kongresi'nde sözlü bildiri olarak sunulmuştur.

${ }^{\alpha}$ Konya Ağız ve Diş Sağlığı Merklezi, Konya

$\beta$ Gazi Üniversitesi Diş Hekimliği Fakültesi Protetik Diş Tedavisi Anabilim Dalı, Ankara
} 
Zirkonya seramikler yapısını oluşturan yoğun kristalin faz nedeniyle oldukça opak görünüme sahiptir ve bu nedenle zirkonya alt yapılı seramik restorasyonlarda ideal estetiğin yakalanabilmesi için alt yapı uygun translüsensliğe sahip veneer seramikler ile kaplanmaktadır. Bununla birlikte, zirkonya restorasyonlarda veneer seramiğin alt yapıdan atması (chipping) ve veneer seramiklerde görülen minör kırıklar klinik olarak en sık görülen başarısızlıklardır. Alt yapı üzerine işlenen veneer seramiğin geometrisi ve kalınlığı ile oklüzal erken kontaklar ve aşındırmadan kaynaklanan mikro kırıklar kohesiv veneer seramik kırıklarının en sık görülen sebeplerindendir., ${ }^{2,4}$

Zirkonya restorasyonlarda veneer seramiğin kırılması durumunda, geleneksel klinik ve laboratuvar işlemleri tekrarlanarak restorasyon ya yenilenir ya da restorasyonun kırılan bölgesi kompozit rezin ve adeziv sistemler kullanılarak hasta ağzında direkt olarak tamir edilir. ${ }^{5}$ Kırılan bir restorasyonun yeniden yapılması ideal bir yöntemdir fakat zaman kaybına neden olur, laboratuvar prosedürlerini tekrarlattırır, pahalıdır ve kalan diş dokusunda yeni bir travmaya neden olur. ${ }^{6}$ $\mathrm{Bu}$ sebepler dikkate alındığında, estetik ve fonksiyonel probleme sebep olmayan küçük kırıklar için ağız içi tamir metodunun hızlı, ucuz ve prosedürlerinin kolay olması bu tedaviyi en etkin ve pratik çözüm haline getirmektedir. ${ }^{7,8}$

Hasta ağzında uygulanan tamir tedavisinin başarısı zirkonya-kompozit rezin ara yüzeyindeki bağlanma dayanımına bağlıdır. ${ }^{9}$ Kompozit rezinin zirkonyaya olan mikromekanik veya kimyasal bağlanma dayanımını artırmak için çeşitli yüzey işlemleri uygulanır. Kumlama, kompozit rezin ve seramik yüzeyi arasında mikromekanik bağlanmayı oluşturmak için uygulanan bir tedavi seçeneğidir. ${ }^{9}$ $\mathrm{Bu}$ işlem genellikle $50-250 \mu \mathrm{m}^{\prime}$ lik $\mathrm{Al}_{2} \mathrm{O}_{3}$ tozlarının 4-6 atmosfer basınçlı kumlama cihazlarından püskürtülmesi esasına dayanmaktadır. ${ }^{10}$ Elmas frezler ile aşındırma, ağız içinde tamir yapılacağı zaman kırık yüzeyinde sıkça kullanılan bir metottur. Aşındırma ile hem kırık yüzeyindeki kontaminasyon kaldırılmış olur ${ }^{11}$ hem de diğer yöntemlere göre gözle görülebilir daha pürüzlü yüzeyler sağlayarak mekanik bağlantı sağlanmış olur. ${ }^{12,13}$

Bu çalışmanın amacı, dört farklı yüzey işlemine tabi tutularak kompozit rezin ile tamir edilmiş zirkonya alt yapının yaşlandırma sonrası kompozit rezin ile olan makaslama bağlanma dayanımının değerlendirilmesidir. Çalışmanın sıfır hipotezi, farklı yüzey işlemlerinin yaşlandırma sonrası kompozit rezin ile zirkonya arasındaki makaslama bağlanma dayanımını etkilemeyeceği yönündedir.

\section{GEREÇ VE YÖNTEM}

\section{Örneklerin hazırlanması}

Sinterlenmemiş zirkonyum dioksit (IPS-e-max Zircad, Ivoclar Vivadent, Schaan, Liechtenstein) seramik bloklarından hassas kesme cihazından yararlanılarak (Isomet Low Speed Saw, Buehler lake Bluff, IL, ABD) 40 adet $(19 \times 15 \times 2 \mathrm{~mm})$ alt yapı örneği elde edildi ve üretici firmaların önerileri doğrultusunda sinterlendi. Zirkonya alt yapı örneklerinin bağlanma yüzeylerinde standardize edilmiş bir yüzey elde etmek için 200, 400 ve 600 gritlik zımpara kağıtları ile su altında parlatıldı. Hazırlanan zirkonya alt yapı örnekleri farklı yüzey hazırlıklarına tabi tutulmak üzere her grupta 10 adet örnek bulunacak şekilde rastgele 4 gruba ayrıldı $(n=10)$.

Grup 1: Aşındırma grubu olup, gruptaki örnekler $120 \mu \mathrm{m}$ 'lik elmas frezler (Acurata, LOS 4209111001, Thurmansbang, Almanya) kullanılarak yüksek hızda su soğutmalı klinik aeratörü ile 10 saniye süre ile aşındırıldı.

Grup 2: Tribokimyasal silika kaplama grubudur. Zirkonya örnekler $30 \mu \mathrm{m}$ silika kaplı $\mathrm{Al}_{2} \mathrm{O}_{3}$ partikülleri ile $10 \mathrm{~mm}$ mesafeden kumlama cihazı kullanılarak (CoJetTM System; 3M ESPE, Seefeld, Almanya) 3 bar basınç altında 10 saniye süre ile pürüzlendirildi.

Grup 3: Örneklere $0.4 \mathrm{MPa}$ hava basıncı altında $10 \mathrm{~mm}$ mesafeden 10 saniye süreyle kumlama cihazı (BEGO, Wilhelm-Herbst-Bremen, Almanya) yardımıla $50 \mu \mathrm{m} \mathrm{Al}_{2} \mathrm{O}_{3}$ partikülleri (Korox 50, Bego, Bremen, Almanya) püskürtüldü.

Grup 4: Örneklere 0.4 MPa basınç altında kumlama cihazı yardımıyla (BEGO, Wilhelm-Herbst-Bremen, Almanya) 110 $\mu \mathrm{m} \mathrm{Al}_{2} \mathrm{O}_{3}$ (Korox 110, Bego, Bremen, Almanya) partikülleri $10 \mathrm{~mm}$ mesafeden 10 saniye süre ile püskürtüldü.

Yüzey işlemlerini takiben tüm gruptaki örnekler ultasonik temizleyicide 6 dakika temizlendi. Örnekler kurutulduktan sonra kompozit uygulanmak üzere standart bir teflon kalıp içerisine yerleştirildi. Zirkonya alt yapı üzerine uygulanacak olan kompozitlerin standardizasyonunu sağlamak amacıyla teflon kalıbın kompoziti oluşturacak olan kısmı $5 \mathrm{~mm}$ çapında $3 \mathrm{~mm}$ yüksekliğinde hazırlanmıştır. Örneklerin kompozit uygulanacak teflon kalıbın örnek yüzeyine sabitlenmesi ile belirlenen $5 \times 3 \mathrm{~mm}^{2}$ 'lik alanına fosfat monomer içerikli adeziv rezin uygulanarak (Single Bond ${ }^{\mathrm{TM}}$ Universal Adhesive, 3M ESPE, St.Paul, MN, ABD) 20 saniye süre ışın gücü $580 \mathrm{~mW} / \mathrm{cm} 2$ olan LED ışın cihazı (Bluephase, Ivoclar-Vivadent, Liechtenstein) ile polimerizasyonu sağlandı (Resim 1). Adeziv rezin uygulamasını takiben tamir kompoziti (Paradigm, Shade:A2, 3M ESPE, St.Paul, MN, ABD) üretici firmanın tavsiyesi doğrultusunda iki tabaka halinde uygulanarak her bir tabakanın 20 saniye süre ile polimerizasyonu sağlandı (Resim 2). Hazırlanan tüm örnekler banyo sıcaklığı $5-55^{\circ} \mathrm{C}$, banyolar arası transfer zamanı 10 saniye, banyoda bekleme zamanı 30 saniye olan 1000 devirlik termal yaşlandırma cihazına yerleştirildi. 


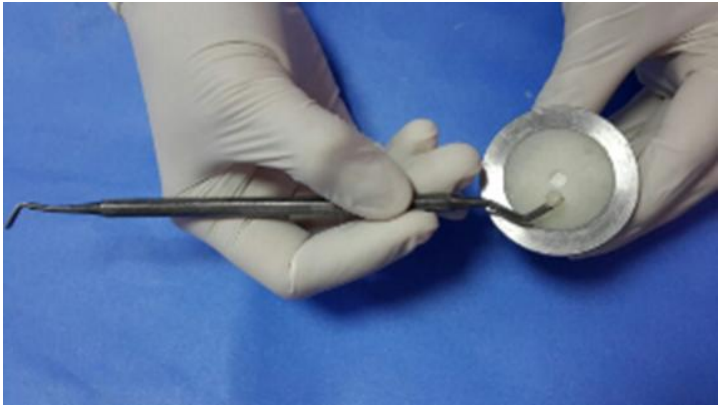

Resim 1.

Teflon kalıba yerleştirilmiş zirkonya örnek üzerine kompozit yı̆̆ılması

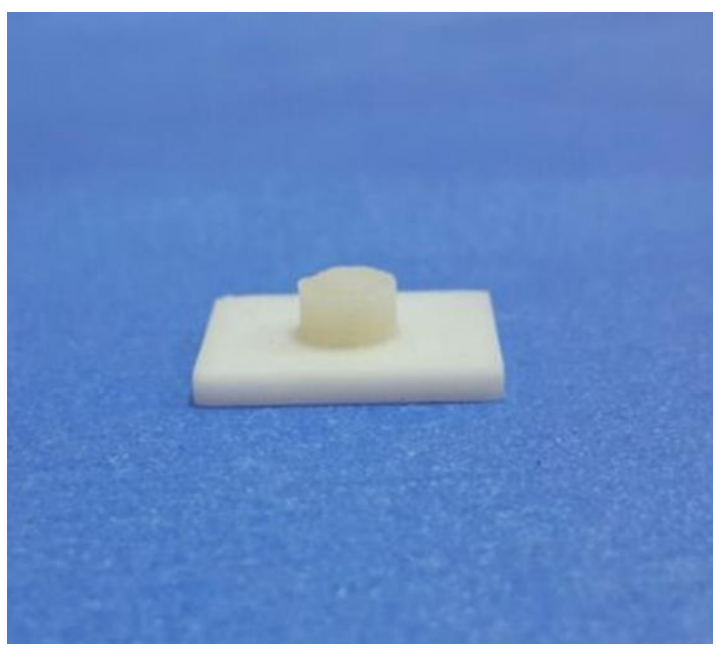

Resim 2.

Kompozit yı̆̆ılarak hazır hale getirilmiş zirkonya örnek

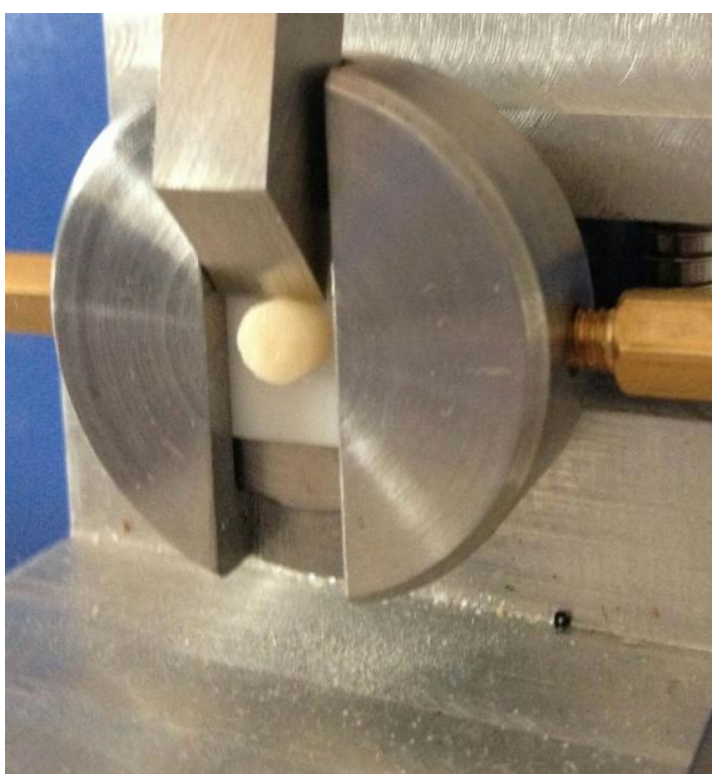

Resim 3.

Özel kalıba yerleştirilmiş örneklere makaslama bağlanma dayanımı testi uygulaması
Tablo 1.

\section{Çalışmada kullanılan materyaller ve üretici firmalar}

\begin{tabular}{|c|c|c|}
\hline Materyal & İçerik & Üretici firma \\
\hline Zirkonya alt yapı & IPS e.max ZirCAD, MO Blok & $\begin{array}{c}\text { Ivoclar Vivadent, Schaan, } \\
\text { Liechtenstein }\end{array}$ \\
\hline Kompozit & $\begin{array}{l}\text { Paradigm Kompozit, } \\
\text { Renk:A2 }\end{array}$ & $\begin{array}{c}\text { 3M ESPE, St. Paul, MN, } \\
\text { ABD }\end{array}$ \\
\hline $\begin{array}{l}\text { Kumlama } 50 \text { ve } \\
110(\mu \mathrm{m})\end{array}$ & $\begin{array}{c}50 \mu \mathrm{m} \text { ve } 110 \mu \mathrm{m} \mathrm{Al} \mathrm{O}_{3} \\
\text { tanecikleri }\end{array}$ & $\begin{array}{c}\text { Corox, Bego, Bremen, } \\
\text { Almanya }\end{array}$ \\
\hline CoJet & $\begin{array}{c}30 \mu \mathrm{m} \text { silika kaplı } \mathrm{Al}_{2} \mathrm{O}_{3} \\
\text { tanecikleri }\end{array}$ & $\begin{array}{c}\text { CoJet }^{\mathrm{TM}} \text { system; 3M ESPE, } \\
\text { Seefeld, Almanya }\end{array}$ \\
\hline $\begin{array}{l}\text { Single Bond } \\
\text { Universal }\end{array}$ & $\begin{array}{l}\text { MDP fosfat monomer, } \\
\text { dimetakrilat rezinler, HEMA, } \\
\text { kopolimer, etanol, su, } \\
\text { başlatıcılar, silan. }\end{array}$ & $\begin{array}{c}\text { 3M ESPE, St.Paul, MN, } \\
\text { ABD }\end{array}$ \\
\hline Elmas Frez & $120 \mu \mathrm{m}$ grit elmas frez & $\begin{array}{c}\text { Acurata, LOS } \\
\text { 4209111001, } \\
\text { Thurmansbang, Almanya }\end{array}$ \\
\hline
\end{tabular}

\section{Test işlemi}

Bin devirlik termal yaşlandırma işlemini takiben makaslama testi için hazır hale getirilen örnekler, hazırlanan özel kalıba sabitlendi ve kalıp üniversal test cihazına yerleştirildi. Test cihazı ucu, zirkonya-kompozit ara yüzeyi ile $90^{\circ}$ açı yapacak şekilde ayarlanarak 0,5 mm/dakika hızla kesme kuvveti uygulandı (Resim 3). Newton (N) cinsinden alınan makaslama bağlantı dayanımı verileri, resin simanı bağlanma alanına bölünerek MPa'ya çevrildi. Bu işlem sırasında kullanılan formül:

Bağlanma dayanımı $(\mathrm{MPa})=$ Kuvvet $(\mathrm{N}) /$ yüzey alanı $\left(\mathrm{mm}^{2}\right)(\mathrm{pi}$ $x r^{2}$ ) olarak tanımlanmıştır. Formüldeki pi değeri sabit sayıyı ifade ederken, $r$ değeri ise simanın bağlandığı dairesel alanın yarıçapını ifade etmektedir.

Makaslama testi sonrasındaki tüm örnek yüzeyleri floresan ışık altında çıplak gözle incelenerek kırılma tipleri kaydedildi.

\section{İstatistiksel analiz}

Çalışmaya ait verilerin istatistiksel analizi SPSS paket programı (SPSS Version:20, Inc, Chicago, IL, ABD) kullanılarak yapılmıştır. Shapiro Wilk normallik testi sonucu veriler normal dağılım gösterdiğinden tek yönlü varyans analizi (ANOVA) yapılarak gruplar arası farklar değerlendirilmiştir. Levene testi sonucuna göre varyansların homojen olduğu gözlenmiştir. ANOVA sonuçlarına göre gruplar arası fark anlamlı bulunduğundan karşılaştırmalar Tukey HSD testi ile yapılmıştır. İstatistiksel anlamlılık düzeyi $p<0.05$ olarak kabul edilmiştir.

\section{BULGULAR}

Bu çalışmanın sonuçlarında en yüksek makaslama bağlantı değerleri CoJet grubunda bulunup farkın diğer gruplara göre istatistiksel olarak anlamlı derecede yüksek olduğu gözlenmiştir. Kumlama 50, kumlama 110 ve aşındırma gruplarındaki fark istatistiksel olarak anlamlı değildir. Gruplar arası ortalamalar ve standart sapmalar Tablo 2'de verilmiştir. 
Tablo 2.

\section{Gruplara ait makaslama bağlanma dayanımı sonuçları (MPa)}

\begin{tabular}{|lcccc|}
\hline \multicolumn{1}{|c}{ Grup } & Ortalama & $\begin{array}{c}\text { Standart } \\
\text { sapma }\end{array}$ & $\begin{array}{c}\text { En } \\
\text { küçük }\end{array}$ & En büyük \\
\hline Grup 1: Aşındırma & $21.51^{\mathrm{a}}$ & 1,72 & 19,42 & 24,65 \\
\hline Grup 2: CoJet $30 \mu \mathrm{m}$ & $28.44^{\mathrm{b}}$ & 3,91 & 22,8 & 35,04 \\
\hline Grup 3: Kumlama $50 \mu \mathrm{m}$ & $19.93^{\mathrm{a}}$ & 2,31 & 16,67 & 23,71 \\
\hline $\begin{array}{l}\text { Grup 4: Kumlama } \\
\mu \mathrm{m}\end{array}$ & $23.38^{\mathrm{a}}$ & 4,35 & 18,73 & 34 \\
\hline Total & 23,32 & 4,51 & 16,67 & 35,04 \\
\hline
\end{tabular}

Aynı sütun içerisindeki farklı üstsimge harfi taşıyan gruplar arasındaki fark istatistiksel olarak anlamlıdır $(p<0.05)$.

Makaslanma testi sonucunda kopma tipleri incelenmiş, tüm gruplarda kompozit materyalinin zirkonya üzerinden tamamen ayrılmış olduğu gözlenmiştir. Bu sonuçlara göre, tüm gruplarda zirkonya ile kompozit rezin arasında adeziv tip kopmanın oluştuğu kaydedilmiştir.

\section{TARTIŞMA}

Dental materyallerdeki gelişmelere rağmen seramik restorasyonların çatlaması ve kırılması klinik bir problem olarak karşımıza çıkmaktadır. ${ }^{14,15}$ Ağız içinde kullanılan tam seramik sistemlerin yaygınlaşması ile seramik tamir sistemlerine olan intiyaç da artmaktadır. Bu noktada, klinisyenlerin ağız içinde seramik tamiri konusunda en etkili ve kolay metodu kullanmaları önem taşır. Bu çalışmada, dört farklı yüzey işlemi uygulanmış zirkonya alt yapının ağız içi tamir kompoziti ile olan makaslama bağlanma dayanımı değerlendirilmiş, klinik olarak en uygun tamir prosedürünün önerilmesi amaçlanmıştır. Çalışmanın sonuçlarına göre, yüzey işlemleri arasında makaslama bağlanma dayanımı açısından anlamlı bir fark olduğundan çalışma başında kurulan sıfır hipotezi reddedilmiştir.

Zirkonya alt yapılı seramik restorasyonlarda bildirilen en temel sorun, alt yapı ile seramiğin bağlantı sorununa bağlı olarak seramiğin zirkonya yüzeyinden ayrılması veya kırılmasıdır. Son yıllarda, zirkonya yüzeyinin çeşitli yüzey işlemlerine tabi tutularak kompozit rezinler ile ağız içi tamiri gündeme gelmiştir. ${ }^{13,16} \mathrm{Bu}$ yüzey işlemleri, hidroflorik asit uygulaması, ${ }^{17}$ yüzeyin silanlanması, silika kaplama, ${ }^{13}$ kumlama, aşındırma, fosfat bağlı monomer içeren rezin uygulaması, SIE (selective infiltration etching), ${ }^{18}$ ve bazı kombine yüzey işlemi uygulamaları, ${ }^{19,20} \mathrm{Nd}$ :YAG ve Er:YAG lazer uygulamaları ${ }^{13,21}$ olarak sayılabilir. Hidroflorik asit ile yüzey pürüzlendirilmesi camsı seramikler ve feldspatik seramiklerde önerilebilen bir metot olmasına rağmen, yüzeyin camsı yapıda olmaması ve silikadan yoksun olması zirkonya yüzeyinin hidroflorik asit uygulamasına karşı dirençli kılmaktadır., 92
Zirkonya yüzeyinin elmas frezlerle döner aletler kullanılarak manuel olarak aşındırılması sonucu kompozit rezinler ile zirkonya arasında yüksek bağlantı değerleri kaydedildiği bildirilmiştir. ${ }^{13,19,23}$ Yüzey aşındırması genel olarak kumlamanın yapılamadığı ağız içi işlemlerde tercih edilmesi gereken bir yöntem olarak bildirilmiştir. ${ }^{19,24,25}$ Bununla birlikte, frez ile aşındırma sonrasında, zirkonyada oluşacak faz değişikliği sonucu zirkonyanın bükülme dayanımında düşüş olduğu ve kırımalara karşı dayanıksız hale geldiği bildirilmiştir. ${ }^{24,26,27} \quad$ Bahsedilen çalışmalarda aşındırma yönteminin kullanıldığı frezler farklı gren büyüklüğüne sahip olduğundan çalışmalardan elde edilen bağlantı değerlerinin bizim çalışmamızla birebir kıyaslanması doğru olmayacaktır.

$\mathrm{Al}_{2} \mathrm{O}_{3}$ ile kumlamanın güçlü bir zirkonya-rezin bağlantısının kurulması için zirkonya yüzeyinde kullanılabilecek etkili bir metot olduğu bildirilmiştir. $^{19}$ Bunun yanı sıra, kumlamanın zirkonya restorasyonların mekanik dayanımını artırdığı belirtilmişse de, ${ }^{20,26,28}$ kumlayla uzun vadede zirkonyanın mekanik dayanımının düşebileceğini bildiren çalışmalar da mevcuttur. ${ }^{29,30}$

Zirkonya yüzeyinin pürüzlendirilmesi ile yüzey alanı artırılarak rezin siman ile zirkonya arasında mikromekanik bir bağlantı kurulduğu bildirilmiştir. ${ }^{21}$ Kumlama, zirkonya yüzey pürüzlülüğünün artırılması için kullanılan en yaygın metotlardan biridir. $^{21}$ Zirkonya yüzeyinin $50 \mu$ m'lik $\quad \mathrm{Al}_{2} \mathrm{O}_{3}$ partikülleri ile kumlanmasında, zirkonya ile kompozit arasında mikromekanik bir bağlantı elde edilirken aynı zamanda zirkonya yüzeyinin yüzey enerjisinin de artırıması hedeflenir. ${ }^{19}$ Yapılan çalışmalarda, zirkonya ile kompozit rezin arasındaki bağlantıyı artırmak için kumlamanın yapılması önerilirken, ${ }^{31,32}$ kumlamanın zirkonya ile kompozit rezin arasındaki bağlantıyı önemli derecede etkilemediğini bildiren çalışmalar da mevcuttur. 33,34

Zirkonya yüzeyinin $50 \mu$ m'lik $\mathrm{Al}_{2} \mathrm{O}_{3}$ ile kumlanması ağız içi tamirlerde önerilen bir metottur. ${ }^{35}$ Yine 110 $\mu$ m'lik $\mathrm{Al}_{2} \mathrm{O}_{3}$ ile kumlamada da zirkonya yüzeyinde yaklaşık $60 \mu$ m'lik bir tabakanın kaldırımasıyla yüksek bir yüzey pürüzlülüğü elde edildiği bildirilmiştir. ${ }^{20,25}$ Kumlamayı takiben fosfat monomer içeren rezin uygulamasıyla zirkonya ile kompozit arasında güçlü bir bağlantı elde edilir. ${ }^{19}$ Çalışmalarda, $110 \mu \mathrm{m} \quad \mathrm{Al}_{2} \mathrm{O}_{3}$ ile kumlama sonrasında güçlü bir bağlantının, ancak zirkonya yüzeyine fosfat monomer uygulaması ile gerçekleşebileceği bildirilmiştir. ${ }^{32,34,36}$ Çalışmamızda ikinci olarak en yüksek bağlantı değeri $110 \mu$ m'lik kumlama grubunda elde edilmiştir. Bu sonuçlara göre aşındırma kapasitesi 
yüksek olan $110 \mu \mathrm{m}$ kumlama ile kompozit rezin arasında sıkı bir mikromekanik bağlantı kurulmuş olabileceği yorumu yapılabilir. Subaşı ve İnan, ${ }^{37}$ yapmış oldukları çalışmada $110 \mu$ m'lik $\mathrm{Al}_{2} \mathrm{O}_{3}$ ile kumlama sonrasında zirkonya yüzeyinde yüksek bir mikromekanik bir bağlantı kurulabileceğini bildirmiştir. Çalışmamızdan elde edilen sonuçlar Subaşı ve İnan'ın ${ }^{37}$ çalışma sonuçları ile uyumluluk göstermiştir. Ne var ki, çalışmamızda yüzey pürüzlülüğü testi yapılmamıştır. Literatürde 50 ve $110 \mu \mathrm{m}$ tanecik büyüklüğüne sahip kumlama çeşitlerini, kompozit rezinin ile zirkonya arasındaki bağlanma dayanımı açısından kıyaslayan çalışmaya rastlanmamıştır. Yüzey pürüzlüğü ile bağlanma dayanımı arasındaki ilişki, gelecek çalışmalarda ele alınabilir.

Son yıllarda tribokimyasal silika kaplama olarak da bilinen yöntemle zirkonya ve rezin kompozit arasında yüksek bağlanma dayanımı elde edildiği rapor edilmiştir. ${ }^{13,33}$ Tribokimyasal silika kaplama yönteminde, zirkonya yüzeyi $30 \mu$ m'lik silika kaplı $\mathrm{Al}_{2} \mathrm{O}_{3}$ partikülleriyle kumlanarak zirkonya yüzeyinde camsı bir yapının oluşması hedeflenir. Silika parçacıkları zirkonya yüzeyine gömülerek yüzeyde kalan silika partikülleri ile rezin arasında kuvvetli bir bağlantı kurulması amaçlanır. Çalışmamızda da en yüksek bağlanma dayanımı değeri silika kaplama grubunda gözlenmiştir. Silika kaplama yöntemini takiben yüzeyde kalan silika tanecikleri ile fosfat monomer ile kompozit rezin kuvvetli bir bağlantı kurmuş olabilir.

Zirkonya yüzeyinin silika kaplama yöntemi ile modifiye edilmesi sonucu adeziv rezinlerle sıkı bir kimyasal bağ yaptığı rapor edilmiştir. ${ }^{13,19}$ Han ve arkadaşlarının ${ }^{11}$ bildirdiğine göre $30 \mu$ m'lik silikon dioksit (silika) partiküllerinin kullanıldığı CoJet sisteminin uygulandığı zirkonya yüzeyi ile fosfat monomeri MDP'nin (10metakriloksidesil dihidrojen fosfat) kullanıldığı tamir sisteminde makaslama bağlanma dayanımı, diğer yüzey işlemlerinin uygulandığı tamir sistemlerine göre anlamlı derecede yüksek bulunmuştur. Çalışmamızda, tribokimyasal silika kaplama yöntemi uygulanan gruptaki bağlanma dayanımı değerleri diğer yüzey işlemleri gruplarına göre anlamlı derecede yüksek bulunmuştur. Son yıllarda yapılan çalışmalarda zirkonya yüzeyinde tribokimyasal silika kaplamanın önerildiği düşünülecek olursa, çalışmamızda elde edilen bulguların literatürle uyumluluk gösterdiği söylenebilir.

Zirkonya yüzeyi ile tamir kompoziti arasındaki bağlantı dayanımını yükseltmek için yüzey işlemlerini takiben yüzeyin fosfat monomeri (MDP monomer) ile ıslatılması gerektiği, böylece mikromekanik bağlantıya ek olarak kimyasal bir bağlantı kurulabileceği bildirilmiştir. ${ }^{32,35}$ Fosfat monomerin metal oksitler ile kimyasal bir bağ yaptığı bilinmektedir. Bu durumda zirkonyum oksitin fosfat monomer ile kimyasal bir bağ yaparak güçlü bir bağlantının oluştuğu düşünülmektedir. ${ }^{32,35}$ Çalışmamızda da fosfat monomer (MDP) esaslı monomer, kompozit rezin öncesi zirkonya yüzeyine uygulanarak kompozit rezin ile dayanıklı bir bağlantı kurulması amaçlanmıştır.
Mekanik bağlanma dayanımı testleri, materyaller arasındaki bağlantıyı test ederek klinik uygulamalara ışık tuttuğu için tercih edilmektedir. Makaslama, mikro makaslama, çekme, mikro çekme, bükülme dayanımı gibi testler literatürde sıklıkla kullanılan testler arasındadır. Makaslama bağlanma dayanımı testi sık kullanılan ve kolay uygulanan ${ }^{38,39}$ bir test olduğundan bizim çalışmamızda da bu test tercih edilmiştir. Çalışmamızda ağız içi uygulamalar taklit edilmeye çalışılmış ve örneklere test öncesi termal yaşlandırma işlemi uygulanmıştır. Bin devirlik termal yaşlandırma uygulaması klinik uygulamaları taklit etse de ağız ortamında oluşan ISı farklarını tam olarak yansıtamadığı, buna rağmen ağız dışı ortamı taklit eden yapay yaşlandırma uygulamaları ile makaslama bağlanma dayanımının düştüğü bildirilmiştir. ${ }^{40}$

Çalışmalarda, zirkonya alt yapı ile tamir kompoziti arasındaki klinik olarak kabul edilebilen en düşük makaslama bağlantı dayanımı 10 Mpa olarak bildirilmiştir. ${ }^{41}$ Çalışmamızda elde edilen tüm gruplara ait makaslama bağlanma dayanımı değerleri bildirilen en düşük değerlerin üzerindedir. $\mathrm{Bu}$ durumda çalışmamızda uygulanan tüm yüzey işlemlerinin ağız içi tamir metodu olarak kullanılabileceği söylenebilir. Farklı çalışmalarda farklı makaslama bağlanma dayanımı değerlerinin elde edilmiş olması, çalışma metodundaki farklılıklar, bağlantı yüzey alanlarındaki farklılıklar ve çalışmalarda kullanılan materyallerin çeşitliliğinden kaynaklanıyor olabilir.

Çalışmamızda tek tip zirkonya alt yapı, kompozit ve adeziv rezin monomer kullanılmıştır. Çalışmamızda yüzey işlemi yapılmayan kontrol grubuna yer verilmemiş, en sık kullanılan ağız içi tamir metotlarının kıyaslanması amaçlanmıştır. Yüzey işlemleri sonrasında örneklerin tarayıcı elektron mikroskobu (SEM) ile incelenmemesi çalışmamızın en büyük limitasyonudur. Gelecekteki yeni çalışmalarda, yüzey işlemlerinin materyal üzerindeki etkisinin topografik değerlendirilmeleri ile yüzey işlemlerinin olası etkileri hakkında yorum yapılabilir. Bununla birlikte, gelecek in vitro çalışmalar, materyal çeşitliliği artırılarak farklı marka ve farklı yüzey işlemleri kombinasyonları kullanılarak planlanabilir.

\section{SONUÇ}

Çalışmanın sonuçlarına göre, zirkonyanın ağız içi tamiri için önerilebilecek yüzey işlemi metodunun, yüksek bağlantı değerleri vermesi açısından, zirkonya yüzeyine tribokimyasal silika kaplama ve ardından adeziv fosfat monomeri uygulaması olduğu söylenebilir. Çalışmadan elde edilen veriler, klinik çalışmalar ve ileri düzey yüzey analiz yöntemleri ile desteklenmelidir.

\section{TEŞEKKÜR}

Yazarlar, termal siklus uygulaması için Dr. Necla Demir'e teşekkür eder. 


\section{KAYNAKLAR}

1. Karakoca S, Yilmaz H. Zirkonyum ve sabit protezlerde kullanımı. Atatürk Üniv Diş Hek Fak Derg 2006; 1: 36-44.

2. Raigrodski AJ, Chiche GJ, Potiket N, Hochstedler $\mathrm{JL}$, Mohamed SE, Billiot S, et al. The efficacy of posterior three-unit zirconium- oxide-based ceramic fixed partial dental prostheses: a prospective clinical pilot study. J Prosthet Dent 2006; 96: 237-44.

3. Yavuzyılmaz H, Turhan B, Bavbek B, Kurt E. Tam porselen sistemleri II. GÜ Diş Hek Fak Derg 2005; 22: 49-60.

4. Sailer I, Fehér A, Filser F, Lüthy H, Gauckler LJ, Schärer $P$, et al. Prospective clinical study of zirconia posterior fixed partial dentures:3-year follow-up. Quintessence Int 2006; 37: 685-93.

5. Blum IR, Nikolinakos $\mathrm{N}$, Lynch $\mathrm{CD}$, Wilson $\mathrm{NH}$, Millar BJ, Jagger DC. An in vitro comparison of four intra-oral ceramic repair systems. J Dent 2012; 40: 906-12.

6. Goia TS, Leite FP, Valandro LF, Özcan M, Bottino MA. Repair bond strength of a resin composite to alumina-reinforced feldspathic ceramic. Int $\mathrm{J}$ Prosthodont 2006; 19: 400-2.

7. Lee SJ, Cheong CW, Wright RF, Chang BM. Bond strength of the porcelain repair system to allceramic copings and porcelain. J Prosthodont 2014; 23: 112-6.

8. Acar Ö. Farklı yüzey hazırlıklarının CAD/CAM hibrit seramiğin kompozit rezin ile tamirine etkisi. Acta Odontol Turc 2016; 33: 121-5.

9. Della Bona A, Borba M, Benetti P, Cecchetti D. Effect of surface treatment on the bond strength of the zirconia-reinforced ceramic to composite resin. Braz Oral Res 2007; 21: 10-5.

10.Fischer J, Stawarczyk B. Compatibility of machined Ce-TZP/Al2O3 nanocomposite and a veneering ceramic. Dent Mater 2007; 23: 1500-5.

11. Han IH, Kang DW, Chung CH, Choe HC, Son MK. Effect of various intraoral repair systems on the shear bond strength of composite resin to zirconia. J Adv Prosthodont 2013; 5: 248-55.

12.Dérand $P$, Dérand $T$. Bond strength of luting cements to zirconium oxide ceramics. Int $\mathrm{J}$ Prosthodont 2000; 13: 131-5.

13. Kirmali O, Barutcigil Ç, Ozarslan MM, Barutcigil K, Harorlı OT. Repair bond strength of composite resin to sandblasted and laser irradiated Y-TZP ceramic surfaces. Scanning 2015; 37: 186-92.

14.Bonfante EA, Sailer I, Silva NR, Thompson VP, Dianne Rekow E, Coelho PG. Failure modes of $Y$ TZP crowns at different cusp inclines. J Dent 2010; 38: 707-12.
15.Abou Tara M, Eschbach S, Wolfart S, Kern M Zirconia ceramic inlay-retained fixed dental prostheses - first clinical results with a new design. J Dent 2011; 39: 208-11

16. Attia A. Influence of surface treatment and cyclic loading on the durability of repaired all-ceramic crowns. J Appl Oral Sci 2010; 18: 194-200.

17. Brentel AS, Ozcan M, Valandro LF, Alarça LG, Amaral R, Bottino MA. Microtensile bond strength of a resin cement to feldspathic ceramic after different etching and silanization regimens in dry nda ged conditions. Dent Mater 2007; 23: 132331.

18.Casucci A, Monticelli F, Goracci C, Mazzitelli C, Cantoro A, Papacchini F, et al. Effect of surface pre-treatments on the zirconia ceramic-resin cement microtensile bond strength. Dent Mater 2011; 27: 1024-30.

19. Qeblawi DM, Muñoz CA, Brewer JD, Monaco EA Jr. The effect of zirconia surface treatment on flexural strength and shear bond strength to a resin cement. J Prosthet Dent 2010; 103: 210-20.

20.Souza RO, Valandro LF, Melo RM, Machado JP, Bottino MA, Ozcan M. Air-particle abrasion on zirconia ceramic using different protocols: effects on biaxial flexural strength after cyclic loading, phase transformation and surface topography. $\mathrm{J}$ Mech Behav Biomed Mater 2013; 26: 155-63.

21.Usumez A, Hamdemirci N, Koroglu BY, Simsek I, Parlar O, Sari T. Bond strength of resin cement to zirconia ceramic with different surface treatments. Lasers Med Sci 2013; 28: 259-66.

22. Thompson JY, Stoner BR, Piascik JR, Smith R. Adhesion/cementation to zirconia and other nonsilicate ceramics: where are we now? Dent Mater 2011; 27: 71-82.

23.Kirmali O, Kapdan A, Harorli OT, Barutcugil C, Ozarslan MM. Efficacy of ceramic repair material on the bond strength of composite resin to zirconia ceramic. Acta Odontol Scand 2015; 73(1): 28-32.

24.Xu HHK, Jahanmir S, Ives LK. Effect of grinding on strength of tetragonal zirconia and zirconia toughened alumina. Mach Sci Technol 1997; 1: 49-66.

25. Kosmac T, Oblak C, Jevnikar P, Funduk N, Marion L. Strength and reliability of surface treated Y-TZP dental ceramics. J Biomed Mater Res 2000; 53: 304-13.

26. Kosmac T, Oblak C, Jevnikar P, Funduk N, Marion $L$. The effect of surface grinding and sandblasting on flexural strength and reliability of Y-TZP zirconia ceramic. Dent Mater 1999; 15(6): 426-33. 
27.Denry IL, Holloway JA. Microstructural and crystallographic surface changes after grinding zirconia-based dental ceramics. J Biomed Mater Res Part B: Appl Biomater 2006;76B:440-8.

28. Guazzato M, Proos K, Quach L, Swain MV. Strength, reliability and mode of fracture of bilayered porcelain/zirconia (Y-TZP) dental ceramics. Biomaterials 2004; 25: 5045-5052.

29. Curtis AR, Wright AJ, Fleming GJP. Theinfluence of simulated masticatory loading regimes on the biaxial flexure strength and reliability of a Y-TZP dental ceramic. J Dent 2006; 34: 317-325.

30.Zhang Y, Lawn BR, Malament KA, Van Thompson $P$, Rekow ED. Damage accumulation and fatigue life of particle-abraded ceramics. Int $\mathrm{J}$ Prosthodont 2006; 19: 442-8.

31. Ozcan M, Kerkdijk VLF. Comparison of resin cement adhesion to Y-TZP ceramic following manufacturers' instructions of the cements only. Clin Oral Investig 2007;13(3):279-282

32. Wolfart $M$, Lehmann $F$, Wolfart $S$, Kern $M$. Durability of the resin bond strength to zirconia ceramic after using different surface conditioning methods. Dent Mater 2007; 23: 45-50.

33. Atsu SS, Kilicarslan MA, Kucukesmen HC, Aka PS. Effect of zirconium-oxide ceramic surface treatments on the bond strength to adhesive resin. J Prosthet Dent 2006; 95: 430-4.

34.Wegner SM, Kern M. Long-term resin bond strength to zirconia ceramic. J Adhes Dent 2000; 2: $139-47$

35. Seabra B, Arantes-Oliveira S, Portugal J. Influence of multimode universal adhesives and zirconia primer application techniques on zirconia repair. $J$ Prosthet Dent 2014; 112: 182-7.

36. Kern M, Wegner SM. Bonding to zirconia ceramic: adhesion methods and their durability. Dent Mater 1998; 14: 64-71.

37. Subaşı G, İnan Ö. Evaluation of the topographical surface changes and roughness of zirconia after different surface treatments. Lasers Med Sci 2012; 27: 735-42.

38. Nishigori A, Yoshida T, Bottino MC, Platt JA. Influence of zirconia surface treatment on veneering porcelain shear bond strength after cyclic loading. J Prosthet Dent 2014;112:1392-8.

39. Cevik P, Cengiz D, Malkoc MA. Bond strength of veneering porcelain to zirconia after different surface treatments. J Adhes Sci Techno 2016; 30: 2466-76.
40.Blatz MB, Sadan A, Martin J, Lang B. In vitro evaluation of shear bond strengths of resin to densely-sintered high-purity zirconium-oxide ceramic after long-term storage and thermal cycling. J Prosthet Dent 2004; 91: 356-62.

41. Kim MJ, Kim YK, Kim KH, Kwon TY. Shear bond strengths of various luting cements to zirconia ceramic: surface chemical aspects. J Dent 2011; 39: 795-803.

Yazışma Adresi:

PInar ÇEViK

Gazi Üniversitesi

Diş Hekimliği Fakültesi

Protetik Diş Tedavisi AD

06510, Emek, Ankara, Türkiye

Tel : +90312 2034192

E-mail: dt_pinarcevik@yahoo.com 